\title{
Combination of microsatellite instability and BRAF mutation status for subtyping colorectal cancer
}

\author{
T T Seppälä ${ }^{\star 1,5}$, J P Böhm ${ }^{2,5}$, M Friman ${ }^{2}$, L Lahtinen ${ }^{2}$, V M J Väyrynen ${ }^{1}$, T K E Liipo ${ }^{1}$, A P Ristimäki ${ }^{3,4}$, \\ M V J Kairaluoma ${ }^{1}$, I H Kellokumpu ${ }^{1}$, T H I Kuopio ${ }^{2}$ and J-P Mecklin ${ }^{1}$ \\ ${ }^{1}$ Department of Surgery, Central Finland Central Hospital, Keskussairaalantie 19, 40620 Jyväskylä, Finland; ${ }^{2}$ Department of \\ Pathology, Central Finland Central Hospital, Keskussairaalantie 19, 40620 Jyväskylä, Finland; ${ }^{3}$ Unit of Pathology and Genetics, \\ HUSLAB, Helsinki University Central Hospital, Haartmaninkatu 8, 00290 Helsinki, Finland and ${ }^{4}$ Department of Pathology and \\ Research Programs Unit, University of Helsinki, Haartmaninkatu 8, 00290 Helsinki, Finland
}

Background: The objective of the study was to examine the role of microsatellite instability (MSI) and $B R A F^{V 600 E}$ mutation in colorectal cancer (CRC) by categorising patients into more detailed subtypes based on tumour characteristics.

Methods: Tumour samples from 762 population-based patients with sporadic CRC were analysed for MSI and BRAF $F^{\mathrm{V} 600 E}$ by immunohistochemistry. Patient survival was followed-up for a median of 5.2 years.

Results: Compared with microsatellite stable (MSS) CRC, MSI was prognostic for better disease-free survival (DFS; 5 years: $85.8 \%$ vs $75.3 \%, 10$ years: $85.8 \%$ vs $72.9 \%, P=0.027$; HR $0.49, \mathrm{Cl} 0.30-0.80, P=0.005$ ) and disease-specific survival (DSS; 5 years: $83.2 \%$ vs $70.5 \%$; 10 years: 83.2 vs $65.0 \%, P=0.004$ ). Compared with $B R A F$ wild type, $B R A F^{V 600 E}$ was a risk for poor survival (overall survival; 5 years: $62.3 \%$ vs $51.6 \%, P=0.014 ;$ HR 1.43, Cl 1.07-1.90, $P=0.009$ ), especially in rectal cancer (for DSS, HR: 10.60, Cl: 3.04-36.92, $P<0.001$ ). The MSS/BRAF V600E subtype was a risk for poor DSS (HR: 1.88, Cl: $1.06-3.31, P=0.030$ ), but MSI/BRAF ${ }^{V 600 E}$ was a prognostic factor for DFS (HR: 0.42, Cl: $0.18-0.96, P=0.039$ ). Among stage I-Il patients, the MSS/BRAF ${ }^{V 600 E}$ subtype was independently associated with poor DSS (HR: 5.32, Cl: 1.74-16.31, $P=0.003$ ).

Conclusions: Microsatellite instable tumours were associated with better prognosis compared with MSS. BRAF ${ }^{V 600 E}$ was associated with poor prognosis unless it occurred together with MSI. The MSI/BRAF V600E subtype was a favourable prognostic factor compared with the MSS/BRAF wild-type subtype. BRAF ${ }^{V 600 E}$ rectal tumours showed particularly poor prognosis. The MSS/ $B R A F^{V 600 E}$ subtype was associated with increased disease-specific mortality even in stage I-II CRC.

Growing evidence suggests that colorectal cancer (CRC) should be subdivided into different prognostic groups defined by molecular biomarker combinations that purportedly reflect the CRC development pathways (Samadder et al, 2013; Phipps et al, 2015). One such group would be defined by microsatellite instability (MSI) that occurs in $\sim 15 \%$ of sporadic CRCs and leads to significant clinical heterogeneity in both phenotype and survival (Ionov et al, 1993).
The most common cause of MSI is sporadic hypermethylation of the promoter area of both $M L H 1$ alleles, resulting in deficient mismatch repair (MMR; Samowitz et al, 2005). Microsatellite instability can also occur due to inherited MMR deficiency, such as Lynch syndrome (LS), which involves autosomal-dominant inheritance of a germline mutation in a major MMR gene (MLH1, MSH2, MSH6, or PMS2) followed by a second mutation later in life.

\footnotetext{
*Correspondence: Dr TT Seppälä; E-mail: toni.seppala@fimnet.fi

${ }^{5}$ These authors contributed equally to this work.
}

Received 6 February 2015; revised 14 April 2015; accepted 21 April 2015; published online 14 May 2015

(c) 2015 Cancer Research UK. All rights reserved 0007-0920/15 
Numerous clinical and histological features have been proposed to differentiate MSI tumours from microsatellite stable (MSS) tumours. However, it remains uncertain whether these features are clinically useful to the extent required for universal MSI screening, and whether such clinical division into subgroups would be beneficial.

In cases of MSI, the presence of the BRAF V600E hotspot mutation practically excludes the possibility of LS, and the clinical utility of the combination of these two markers is well established (Funkhouser et al, 2012). BRAF ${ }^{V 600 E}$ shows an independent negative prognostic association with survival in MSS CRC (Samowitz et al, 2005; Ogino et al, 2012; Phipps et al, 2012), but associations with the combination of MSI and BRAF have not been thoroughly investigated. Recent findings indicate that the prognostic potential of MSI overrides the negative prognostic potential of $B R A F^{V 600 E}$, thus eliminating the deleterious role of $B R A F^{V 600 E}$ within the MSI subgroup (Hamilton, 2013; Lochhead et al, 2013). International guidelines suggest using both MSI and $B R A F$ immunohistochemical (IHC) staining for LS screening algorithms; therefore, these markers are increasingly available for clinical use (Palomaki et al, 2009; Weissman et al, 2012; Vasen et al, 2013).

The present study aimed to elucidate the role of MSI and $B R A F^{V 600 E}$ in a population-based setting using patient material treated according to 21 st century guidelines. The findings provide a basis for the routine clinical use of MMR and BRAF status.

\section{MATERIALS AND METHODS}

Patients. The Central Hospital of Central Finland exclusively serves a defined catchment area of $\sim 274000$ people around Jyväskylä, Finland. The present study included all consecutive patients $(n=1088)$ who underwent major bowel resection for CRC between 2000 and 2010. Tissue microarray (TMA) of a representative tumour sample was available for analysis from 799 patients. Good-quality IHC for MSI were available for 762 patients. Compared with the included subjects, those who dropped out did not substantially differ in age, sex, tumour location, or Union for International Cancer Control (UICC) stage.

Ethical aspects. The study was approved by the Central Finland Central Hospital's ethical committee. Authorisation for use of the patient registry was obtained from the National Supervisory Authority for Welfare and Health (Valvira).

Clinical evaluation. Tumours were classified based on their exact location. Tumours situated from the caecum through the transverse colon were deemed proximal colon tumours. Tumours resected from the descending and sigmoid colon from the splenic flexure down to $15 \mathrm{~cm}$ proximal from the anal verge were considered distal colon tumours, and those more distally located were classified as rectal tumours. The specimens were macroscopically examined and histologically studied by an experienced histopathologist following UICC guidelines (sixth edition). The histopathologist also performed pTNM staging regarding tumour size and nodal status. Staging was completed (M) by the treating surgeon based on data from imaging and physical examination (usually a body CT scan). Those patients with inadequate specimen for complete pTNM classification (e.g., transanal extirpation of the tumour, $n=10$ ) were excluded from analyses that required stage. For 574 patients, the operation was elective with a radical result (R0).

Follow-up. For study purposes, a surgeon reviewed all stage assignments along with the pathology and radiology statements, and surgery report. Liver and lung metastases found within 6 months of operation were considered synchronous when determining the final pTNM UICC stage.
Medical records were carefully reviewed. We retrieved information regarding type of surgery (laparoscopic or conventional), parameters reflecting surgical quality, surgical result (i.e., radical/ palliative), possible special circumstances (e.g. emergency surgery), and surgical complications. The exact date and location of CRC local or distal recurrence, occurrence of metastases or metachronous CRC, and the possible interventions were also recorded. The dates and official causes of death were retrieved from death certificates, with permission from the Finnish Cause of Death Registry (collected and updated by Statistics Finland, a government authority). In cases of postoperative death (within 30 days), the cause of death and the role of cancer in the event were assessed individually. All medical data regarding preoperative diagnosis, surgery, recurrence, clinical staging, adjuvant treatment, clinical follow-up, and cause of death were re-assessed and recorded to our database by a surgery specialist. The current vital status of each patient was reviewed by confirming deaths from the hospital's patient registry or, if uncertain, from the service of the Population Register Centre on the 1 November 2014. Median follow-up was 5.2 years (interquartile range 6.4 years).

Tumour sampling. The resected specimens were delivered to the pathology department as fresh tissue samples. After formalin fixation and macroscopic evaluation, the tissue samples were embedded in paraffin, and TMA blocks were prepared from the formalin-fixed paraffin-embedded tissue (FFPE) samples. From each FFPE sample, 0.6-mm-diameter tissue cylinders were punched out from the previously marked representative tumour areas and set into a recipient paraffin block using the Manual Tissue Microarrayer MTA1 (Beecher Instruments Inc., Sun Prairie, WI, USA). From these TMA punches, $2-\mu \mathrm{m}$-thick sections were cut. Tissue microarray blocks included one punch from normal mucosa for each patient. One to four representative punches were included from tumour tissue. Four punches were taken from majority of the cases. If the tissue sample was unrepresentative, the data were not included to the statistical analyses.

Immunohistochemistry. For all included tumour samples, we performed a universal screening for loss of MMR protein expression. To determine MMR status, IHC analysis was performed for expressions of MLH1, PMS2, MSH2, and MSH6. Following standard procedures, IHC stainings were applied to the 2- $\mu$ m FFPE TMA sections using the LabVision Autostainer 480 (Thermo Fisher Scientific, Fremont, CA, USA) and BrightVision + polymer detection kit (ImmunoLogic BV, Duiven, The Netherlands). For MLH1, MSH2, MSH6, and PMS2, antigen retrieval was performed by incubation with $1 \mathrm{~mm}$ EDTA/10 mM Tris/HCl buffer ( $\mathrm{pH} 9)$ at $99^{\circ} \mathrm{C}$ for $15 \mathrm{~min}$. The utilised antibody dilutions were 1:100 for MLH1 (Novocastra, Leica Biosystems, Nussloch, Germany; NCL-L-MLH1), 1:150 for MSH2 (Oncogene Research Products, Cambridge, MA, USA; NA27), 1:50 for MSH6 (Cell Marque, Rocklin, CA, USA; 287M-16), and 1:400 for PMS2 (BD Pharmingen, Franklin Lakes, NJ, USA; 556415). A 60-min incubation time was used for all antibodies. Normal MLH1, PMS2, MSH2, and MSH6 expressions in tumour samples were detectable as undisputed nuclear staining in neoplastic epithelial cells. Loss of expression was indicated by a lack of expression in tumour cells combined with the staining of internal positive controls (stromal cells or blood vessels). Tissue samples that exhibited positive staining for all four markers were considered MSS. Cases that were undisputedly negative for at least one of the four markers were classified as MSI (Shia, 2008).

To determine the BRAF status, samples were stained for the $B R A F^{V 600 E}$ hotspot mutation using a mutation-specific antibody (clone VE1, Spring Bioscience, Pleasonton, CA, US). Immunohistochemical staining was performed as described above. Antigen retrieval was performed by incubation with $1 \mathrm{~mm}$ EDTA/10 mM Tris/ $\mathrm{HCl}$ buffer $(\mathrm{pH} 8)$ at $99^{\circ} \mathrm{C}$ for $25 \mathrm{~min}$. The antibody was 
diluted $1: 100$, and a 60-min incubation was used. Positive staining indicated $B R A F^{V 600 E}$ while the lack of staining indicated wild-type $B R A F$ (Thiel et al, 2013). BRAF ${ }^{V 600 E}$ mutation-specific antibody is highly sensitive and specific in comparison with PCR-based methods or sequencing (Thiel and Ristimäki, 2013).

The IHC stains for all protein expressions were evaluated by an experienced histopathologist (JPB). In cases with uncertain staining results, a second opinion was obtained from another histopathologist (THIK). Immunohistochemical stainings were always assessed without awareness of the clinical data.

Statistical analysis. For analysis, the patients were stratified according to the biological subtypes MSI/MSS and $B R A F^{V 600 E} /$ $B R A F$ wild type, both separately and in combinations.

For categorical variables, $\chi^{2}$-tests or contingency tables were used to investigate the differences between MSI, MSS, BRAF ${ }^{V 600 E}$, and $B R A F$ wild-type groups, and the total population. Multiplegroup differences were tested using one-way analysis of variances with Bonferroni post hoc correction. A $P$-value $<0.05$ was considered statistically significant. Statistical analyses were performed using SPSS Statistics for Mac (release 19.0.0; SPSS Inc., Chicago, IL, USA).

Kaplan-Meier analysis was used to create survival curves, and a log-rank test was used to test the between-subgroup differences in survival curves. Cox regression with proportional hazard analysis was used to evaluate the survival hazard ratio (HR) between groups. Regression models included adjustments for age, sex, tumour location, American Society of Anaesthesiologists (ASA) class, and type of surgery. Separate analyses were conducted to evaluate overall survival (OS), disease-specific survival (DSS), and disease-free survival (DFS; relapse-free survival). Only variables with $P \leq 0.20$ in univariate analysis were entered in the multivariate analysis. For analysis of CRC-specific survival, patients who died from causes other than CRC were censored to the date of death. For analysis of DFS, the date of CRC recurrence after radical surgery was used as an end point. Subjects who were operated with a known non-radical result or who died within 30 days postoperatively for causes other than CRC were excluded from analyses of DSS or DFS.

\section{RESULTS}

The final analysis included a total of 762 patients with IHC results for four tumour MSI markers. Of these patients, 111 (14.6\%) showed a loss of MMR protein expression that was considered the result of MSI, and $94(12.3 \%)$ had tumours with $B R A F^{V 600 E}$. $B R A F^{V 600 E}$ was found in 60 cases with MSI $(54 \%)$ and 34 cases of MSS (5.2\%). Only six out of 191 rectum cancer patients had an MSI tumour, of which three also included $B R A F^{V 600 E}$.

Age and sex. Tables $1 \mathrm{~A}$ and $1 \mathrm{~B}$ present the demographical information of the study population and the subgroups, together with tumour location, staging, molecular markers, lymph node harvest, and follow-up data. Microsatellite instability prevalence increased with age in the study population. Microsatellite instability was strongly associated with female gender, proximal tumour location, and poorly differentiated histology. Compared with men, women showed higher incidences of both MSI and $B R A F^{V 600 E}$. Microsatellite instability incidence increased with age among women but not in men (Table 2). We identified no sex-related differences in the distribution of tumour stages or differentiation (grade). Patients with tumours with $B R A F^{V 600 E}$ were older than those with $B R A F$ wild type. Accordingly, patients of the MSI $B R A F^{V 600 E}$ subtype were significantly older than other groups.

Tumour invasion and metastases. In general, MSI tumours were less likely to have metastasised to local lymph nodes (LN) compared with MSS tumours (30.5 vs 42.2\%). The LN harvest was $15 \mathrm{LN} /$ specimen in MSI tumours, $11 \mathrm{LN} /$ specimen in MSS tumours, $15 \mathrm{LN} /$ specimen in $B R A F^{V 600 E}$ tumours, and $11 \mathrm{LN} /$ specimen in $B R A F$ wild-type tumours. Among MSS/BRAF ${ }^{V 600 E}$ tumours, $64.7 \%$ were nodal positive $(\mathrm{N}+$; Table $1 \mathrm{~A})$.

Compared with MSI tumours, MSS tumours were more than three times more likely to have sent distant metastases $(M+)$. $\mathrm{M}+$ cases comprised $47.1 \%$ of the MSS/BRAF $F^{V 600 E}$ subtype and only $3.3 \%$ of the MSI/BRAF $F^{V 600 E}$ subtype. Accordingly, stage IV was most common in the MSS/BRAF $F^{V 600 E}$ group and least common among MSI cases irrespective of BRAF status (Table 1A). Right-sided tumours were associated with MSI and $B R A F^{V 600 E}$, being most common in the MSI/ BRAF $F^{V 600 E}$ subgroup (Table 1B).

Impact of MSI and BRAF status to prognosis. In the total study population, including the patients who underwent operations for emergency conditions or palliation, the overall 5-year survival was $60.8 \%$ and DSS was $72.3 \%$ (Table 3). Among all electively and radically operated patients (R0; $n=574$ ) the 5 -year DSS was $85.0 \%$ and DFS was $78.6 \%$. Compared with the other subtype groups, $B R A F^{V 600 E}$ MSS tumours were more likely to develop recurrence during follow-up after elective operation with radical outcome, but the subgroups were too small to reliably compare locoregional and distal recurrences (Table 1B).

Compared with MSS cancer, MSI was a prognostic factor for DFS and DSS (5-year DFS: $75.3 \%$ vs $85.8 \%$, 10-year DFS: $72.9 \%$ vs $85.8 \%, P=0.027$; 5 -year DSS: $70.5 \%$ vs $83.2 \%$, 10 -year DSS: $65.0 \%$ vs $83.2 \%, P=0.004$; Figure $1 \mathrm{~A}$ ), but not for OS in univariate analysis. $B R A F^{V 600 E}$ alone was an adverse prognostic factor for OS (5-year OS: $52.2 \%$ vs $62.3 \%, P=0.014$ ) but not for CRC-specific survival. For DSS, univariate analysis showed that the HR for MSI vs MSS was 0.49 (CI: $0.30-0.80, P=0.005)$. Univariate analysis of $B R A F^{V 600 E}$ vs $B R A F$ wild type revealed $\mathrm{HR}$ values of 1.14 (CI: $0.98-$ $1.33, P=0.088)$ for DSS and $1.43(\mathrm{CI}: 1.07-1.90, P=0.015)$ for OS.

Prognostic factors in multivariate analysis. UICC stage, operation type, and combinations of MSI/MSS and $B R A F^{V 600 E} / B R A F$ wild type were significant in univariate analysis, and therefore entered in all multivariate analyses. In addition, age, sex, and ASA class were included in the model of OS. Both MSI and $B R A F^{V 600 E}$ alone lost their independent prognostic significance when UICC stage was added to the model. BRAF $F^{V 600 E}$ seemed to show a negative effect on DSS in rectal cancer in a multivariate model, but the numbers were small (for DSS, HR: 10.60, CI: 3.04-36.92, $P<0.001$; for OS, HR: 4.51, CI: $1.92-10.60, P<0.001 ; n=8$; Figure 1B).

Table 4 presents multivariate analyses for combinations of MSI/ MSS and BRAF $F^{V 600 E} / B R A F$ wild type. The MSS/BRAF $F^{V 600 E}$ subtype was an independent factor associated with poor DSS and OS (for DSS, HR: 1.88 , CI: $1.06-3.31, P=0.030$; Figure $1 \mathrm{C}$; for OS, HR: 1.87, CI: $1.17-3.00, P=0.009)$. Univariate analysis showed a protective effect of the MSI/BRAF ${ }^{V 600 E}$ subtype (for DSS, HR: 0.47 , CI: $0.23-0.96, P=0.039)$ compared with MSS/BRAF wild type, but the difference did not reach significance in the multivariate model. However, the MSI/BRAF ${ }^{V 600 E}$ subtype was an independent prognostic factor for better DFS in the multivariate model (HR: 0.42 , CI: $0.18-0.96, P=0.039)$. Among patients with stage I-II tumours, MSS/BRAF ${ }^{V 600 E}$ subtype was an independent factor for poor DSS compared with MSS/BRAF wild type (HR: 5.32, CI: 1.7416.31, $P=0.003$; Figure 1D).

\section{DISCUSSION}

MSI CRCs have a favourable prognosis despite their characteristically poor histological differentiation (Boland et al, 1998; Benatti, 2005; Samowitz et al, 2005). They also have a reduced 


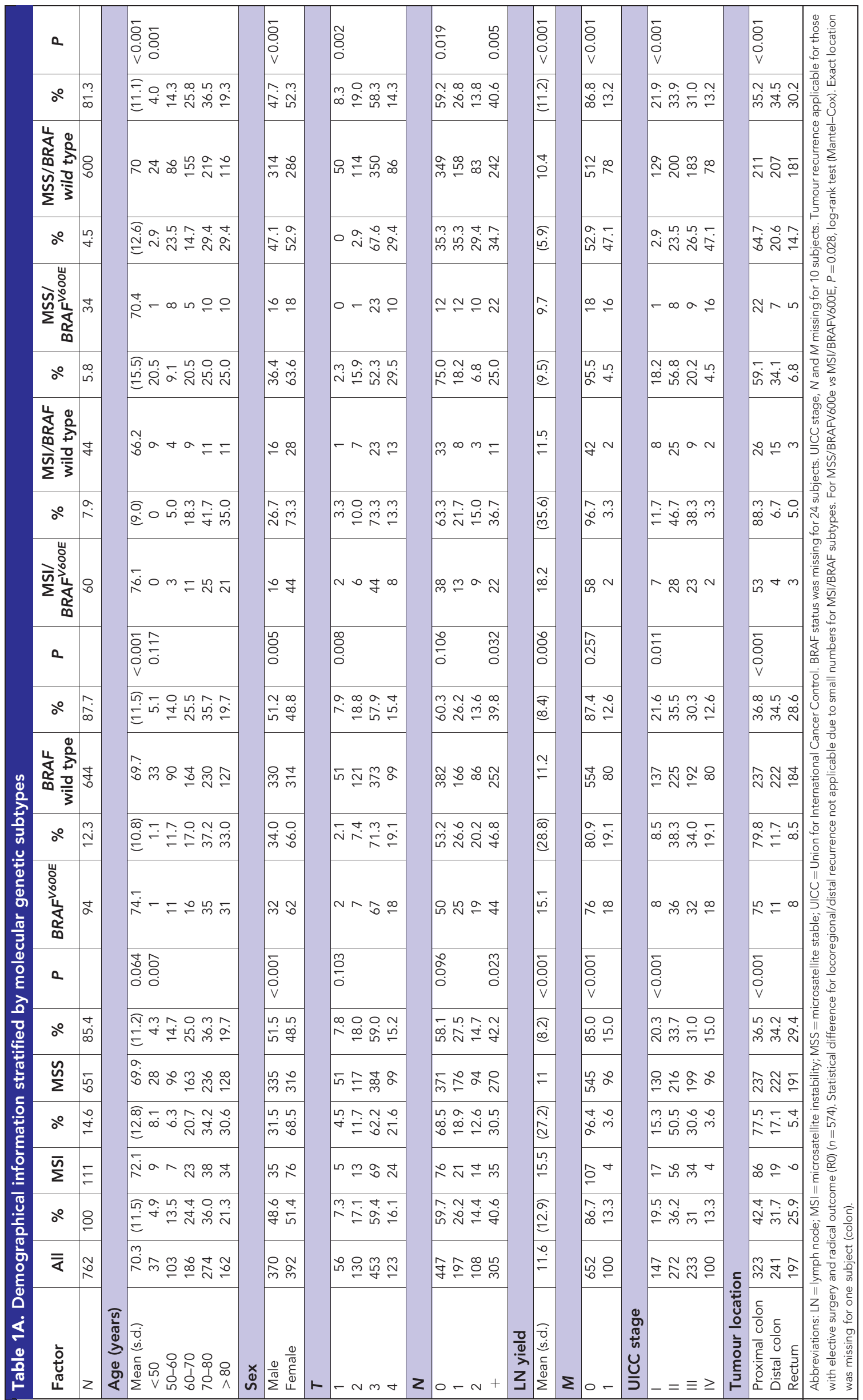




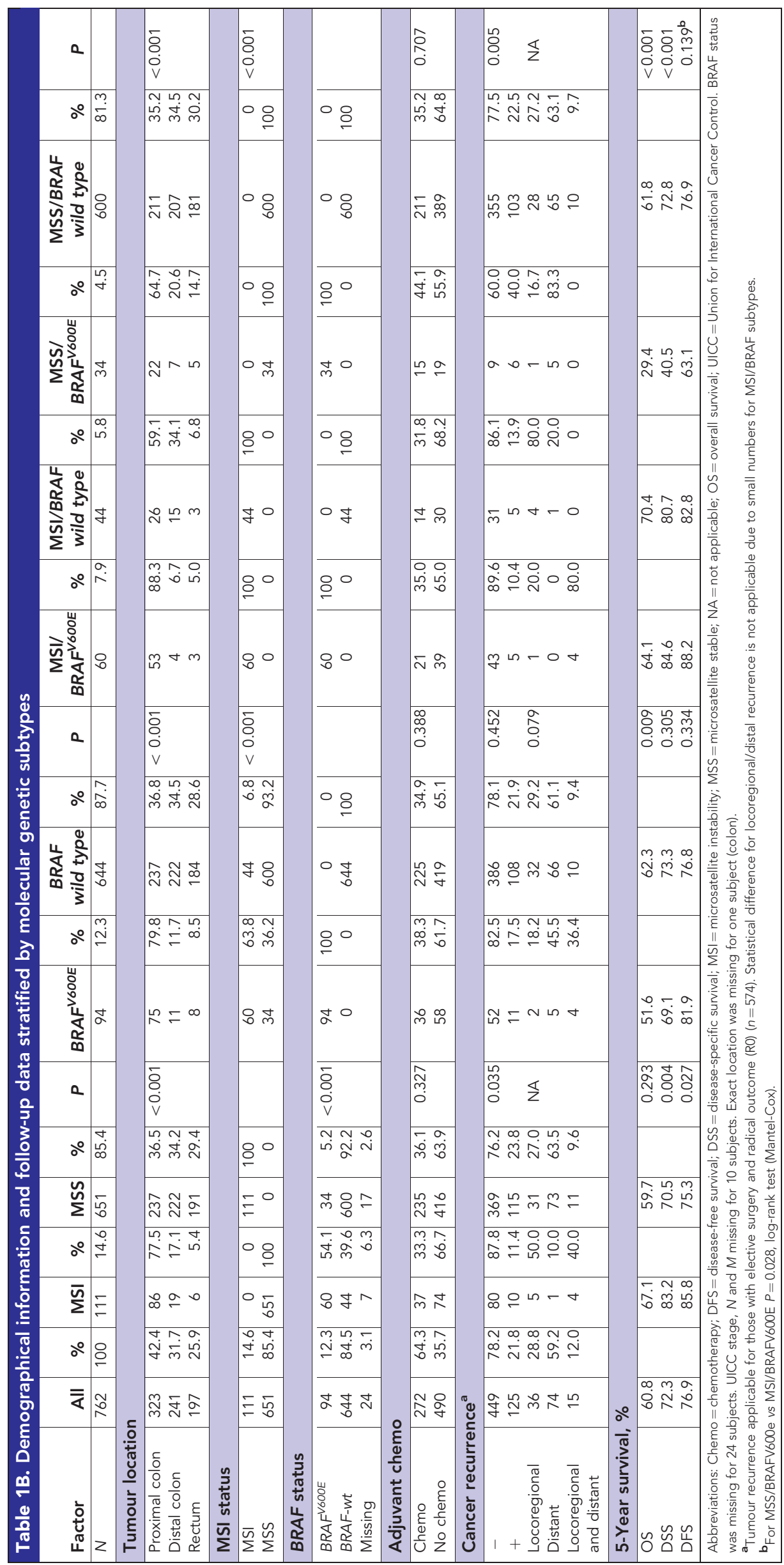


likelihood of both local and distal metastasis, which is suggested by the lower incidence of stages III-IV (Malesci et al, 2007; Hutchins et al, 2011). Microsatellite instability contributes to improved survival by predicting a lower pathologic stage at diagnosis, and predicts more favourable outcome even within the same stage (Gryfe et al, 2000; Popat, 2004; Benatti, 2005).

This study presents the results of analysing tumour samples from a population-based cohort of CRC patients who were residing within a defined catchment area and treated by modern guidelines in the 2000s. Our findings demonstrate the prognostic relevance of $\mathrm{MSI} / B R A F^{V 600 E}$ subtyping in a real-life clinical setting. Our data confirmed some previous inconsistent findings, including the favourable CRC-specific prognosis of MSI/BRAF $F^{V 600 E}$ tumours compared with MSS/BRAF wild-type tumours, which was suspected by Lochhead et al (Lochhead et al, 2013; Toon et al, 2013). We also confirmed the previously described negative prognostic effect of $B R A F^{V 600 E}$ among MSS tumours (Samowitz et al, 2005; Ogino et al, 2009; Roth et al, 2010; Phipps et al, 2012; Toon et al, 2013; Phipps et al, 2015), but we did not find any prognostic significance of $B R A F^{V 600 E}$ within the MSI group.

Strikingly, among patients with stage I-II CRC, we found a patient subgroup with a significantly worse survival than others, which may impact current adjuvant treatment guidelines. The main unanswered clinical question related to MSI and BRAF status relates to the need for and usefulness of postoperative adjuvant therapy in stage I-III CRC. Our present findings indicate that patients with the MSS/BRAFV600E subtype are in danger of increased CRC mortality even in stage I-II and require a more aggressive adjuvant treatment approach (Figure 1D). Combinations with fluorouracil-based (5FU) chemotherapy reportedly do not improve DFS of MSI patients, but improve the course of MSS CRC (Sargent et al, 2010). Also, patients with MSI tumours generally do well without chemotherapy (Hutchins et al, 2011). In the present study, only stage III and IV patients were referred to an oncologist for adjuvant chemotherapy-primarily FOLFOX (folic acid $+5 \mathrm{FU}+$ oxaliplatin) or FOLFIRI (folic acid $+5 \mathrm{FU}+$ irinotecan). Among the stage III MSI CRC patients, $74 \%$ received adjuvant chemotherapy, without showing any survival benefit compared with those who did not (data not shown). It might be beneficial to further target adjuvant chemotherapy to the stage III MSI CRC patients with the worst prognosis. The rationale behind also administering adjuvant chemotherapy to the stage II MSS CRC patients with the worst prognosis should be studied further.

In our study, the eight subjects with rectal cancer and a $B R A F^{V 600 E}$ showed extremely poor survival, with an HR of 10.6 for CRC death (Figure 1C). This differs from the findings in a series of 11 patients presented by Phipps et al (2012) and from the results presented by Samowitz et al (2005), in which the rectum cancer was not reported to stand out with substantially worse prognosis. Most studies include only small numbers of rectal cancer cases, if any, compared with colon cancer cases. Furthermore, BRAF ${ }^{V 600 E}$ seems to be rare in rectal cancer. The present finding of a potentially worse prognosis in MSS/BRAF $F^{V 600 E}$ rectal cancer compared with MSS/BRAF V600E colon cancer has not been previously reported, and must be verified in a larger setting.

Many of our patients were followed up to over 10 years. No disease-specific CRC deaths occurred in the MSI group after 2.7 years, but events continued to occur even up to 10 years in the MSS group (Figure 1A). In addition, only one recurrence was noted in the MSI group after 2 years of DFS (at 4.8 years), whereas several recurrences were observed in the MSS group even after 5 years. Most previous studies have only reported the 5-year DSS and DFS. These observations may suggest that different follow-up schedules should apply according to MSI status.

We found a significant difference in the LN yield related to MSI, which is a relatively new finding. Earlier reports have described the possible macroscopic growth of LNs (Sloothaak et al, 2014) and
Table 2. MSI prevalence and case demographical information by gender

\begin{tabular}{|c|c|c|c|c|c|c|}
\hline & $\begin{array}{c}\text { Male } \\
\text { Total } \\
N\end{array}$ & $\begin{array}{c}\text { MSI } \\
N(\%)\end{array}$ & $P$ & $\begin{array}{c}\text { Female } \\
\text { Total } \\
\mathbf{N}\end{array}$ & $\begin{array}{c}\text { MSI } \\
\text { N (\%) }\end{array}$ & $P$ \\
\hline Total & 370 & $35(9.5)$ & & 392 & $79(19.8)$ & \\
\hline \multicolumn{7}{|c|}{ Age (years) } \\
\hline $\begin{array}{l}<50 \\
50-60 \\
60-70 \\
70-80 \\
>80\end{array}$ & $\begin{array}{r}13 \\
49 \\
93 \\
153 \\
62\end{array}$ & $\begin{aligned} & 3(23.1) \\
& 4(8.2) \\
& 9(9.7) \\
& 13(8.5) \\
& 6(9.7)\end{aligned}$ & 0.544 & $\begin{array}{r}24 \\
54 \\
93 \\
121 \\
100\end{array}$ & $\begin{array}{c}6(25.0) \\
3(5.6) \\
14(15.0) \\
25(20.7) \\
28(28.0)\end{array}$ & 0.011 \\
\hline
\end{tabular}

\section{Tumour location}

\begin{tabular}{|l|c|c|c|r|c|c|}
\hline Proximal colon & 138 & $26(18.8)$ & $<0.001$ & 185 & $60(32.4)$ & $<0.001$ \\
Distal colon & 113 & $6(5.3)$ & & 128 & $13(10.2)$ & \\
Rectum & 118 & $3(2.5)$ & & 79 & $3(3.8)$ & \\
\hline
\end{tabular}

\begin{tabular}{|l|r|c|r|r|r|r|}
\hline Stage \\
\hline I II & 78 & $6(7.7)$ & 0.222 & 69 & $11(15.9)$ & 0.008 \\
III & 124 & $16(12.9)$ & & 148 & $40(27.0)$ & \\
IV & 108 & $11(10.2)$ & & 125 & $23(18.4)$ & \\
Grade & 57 & $2(3.5)$ & & 43 & $2(4.7)$ & \\
\hline G1 & 114 & $8(7.0)$ & 0.006 & 133 & $20(15.2)$ & $<0.001$ \\
G2 & 209 & $16(7.7)$ & & 196 & $27(13.8)$ & \\
G3 (+mucinous) & 47 & $11(23.4)$ & & 61 & $28(45.9)$ & \\
G4 & 0 & 0 & & 2 & $1(50.0)$ & \\
\hline
\end{tabular}

Abbreviations: $\mathrm{MSI}=$ microsatellite instability; $\mathrm{UICC}=$ Union for International Cancer Control. $P$-value for $\chi^{2}$-tests, MSI subgroup vs total within gender. UICC stage missing for 10 subjects ( 3 males and 7 females). Exact location missing for one subject (male).

Table 3. Colorectal cancer disease-specific 5-year survival in MSI and MSS (\%)

\begin{tabular}{|l|c|c|c|c|c|c|c|}
\hline & All & MSI & MSS & Colon & Rectum & $\begin{array}{c}\text { MSI } \\
\text { colon }\end{array}$ & $\begin{array}{c}\text { MSS } \\
\text { colon }\end{array}$ \\
\hline N & 752 & 111 & 651 & 561 & 191 & 105 & 456 \\
\hline Stage I & 94.6 & 100.0 & 94.0 & 96.1 & 92.3 & 100.0 & 95.4 \\
\hline Stage II & 86.0 & 92.0 & 84.4 & 86.8 & 82.6 & 91.7 & 85.2 \\
\hline Stage III & 67.9 & 71.6 & 67.4 & 68.3 & 66.7 & 72.8 & 67.5 \\
\hline Stage IV & 14.0 & 25.0 & 14.6 & 12.3 & 18.2 & 0.0 & 13.1 \\
\hline All patients & 72.3 & 83.2 & 70.5 & 72.4 & 72.1 & 83.3 & 69.9 \\
\hline $\begin{array}{l}\text { Abbreviations: MSI =microsatellite instability; MSS=microsatellite stable. Table includes all } \\
\text { elective, palliative and emergency surgery. Results are from Kaplan-Meier analysis. For 10 } \\
\text { patients, the TNM stage was incomplete due to transanal or endoscopic removal of the } \\
\text { tumor. }\end{array}$
\end{tabular}

consequent greater LN harvest (Belt et al, 2012; Berg and Guriby, 2013). Despite the higher number of LNs found, there were significantly fewer LN metastases in MSI CRCs (Table 1A). As patients with MSI tumours have better outcome than patients with MSS tumours (Gryfe et al, 2000; Popat, 2004; Aparicio et al, 2012; Merok et al, 2013), the peritumoural immune response may play an imperative role in the defence (Galon et al, 2014). The improved survival may be owing to a high number of cytotoxic $\mathrm{T}$ lymphocytes and other favourable differences in the tumour microenvironment (Guidoboni et al, 2001; Boissière-Michot et al, 2014; Richards et al, 2014). Our hypothesis is that the more prominent immune response in MSI leads to LN enlargement to a more easily detectable and macroscopically visible size. However, there may be other explanations. The greater LN harvest could also have resulted from the balance between right/left and colon/rectum in our material, as there was a considerable shift towards rightsided colon tumours in MSI. In addition, rectal tumours tend to have fewer investigated LNs. 

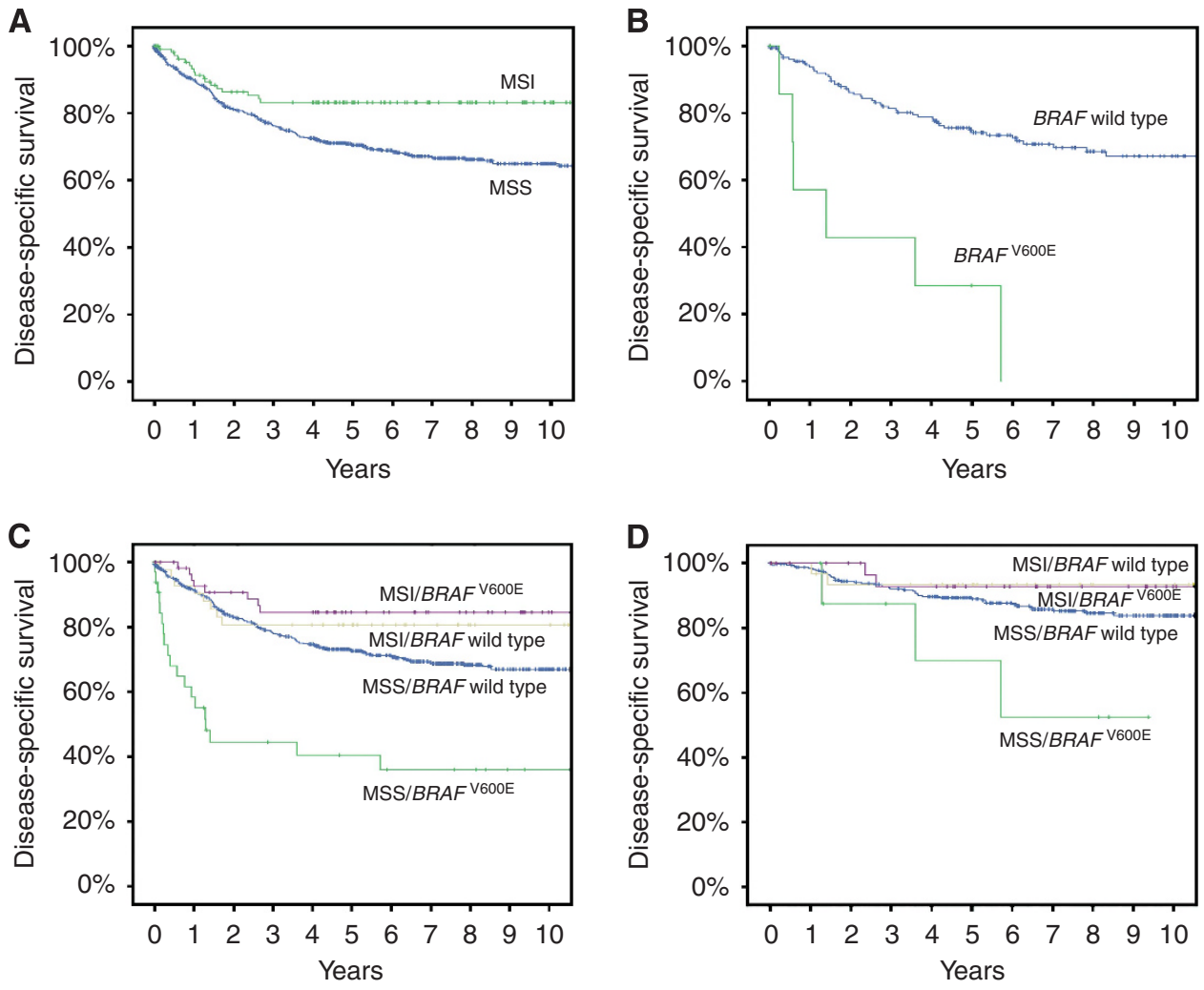

Figure 1. (A) Colorectal cancer (CRC) disease-specific survival (DSS) of patients with microsatellite instable (MSI; $n=111$, green line) and with microsatellite stable (MSS) tumours ( $n=651$, blue line). Five-year survival: MSI, $83.2 \%$, MSS, 70.5\%. Ten-year survival: MSI, $83.2 \%$; MSS, $65.0 \%$. $P=0.004$ for log-rank test (Mantel-Cox). (B) Rectal cancer DSS of patients with $B R A F^{V 600 E}(n=8$, green line) and wild-type BRAF tumours (BRAF wild type, $n=185$, blue line). Five-year survival: $B R A F$ wild type, $73.3 \% ; B R A F^{V 600 E}, 28.6 \%$. Ten-year survival: BRAF wild type, $46.3 \%$; $B R A F^{V 600 E}$, $0 \% . P<0.001$ for log-rank test (Mantel-Cox). (C) Colorectal cancer DSS of subtypes according to the following combinations of MSI and BRAF

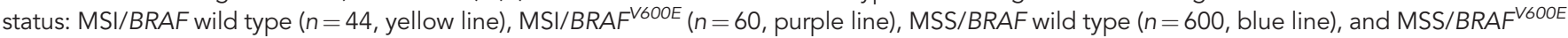
( $n=34$, green line). Five-year survival: MSI/BRAF wild type, 80.7\%; MSI/ BRAF ${ }^{V 600 E}, 84.6 \% ; \mathrm{MSS} / B R A F$ wild type, $72.8 \% ; \mathrm{MSS} / B R A F^{V 600 E}, 40.5 \%$. $P<0.001$ for log-rank test (Mantel-Cox). (D) Colorectal cancer DSS of patients with stage I-II disease according to the following combinations of $\mathrm{MSI}$ and BRAF status: MSI/BRAF wild type ( $n=33$, yellow line), MSI/BRAF ${ }^{V 600 E}$ ( $n=35$, purple line), MSS/BRAF wild type ( $n=329$, blue line), and $M_{S S / B R A F^{V 600 E}}(n=9$, green line). Five-year survival: MSI/BRAF wild type 93.4\%; MSI/BRAF V600E 92.9\%; MSS/BRAF wild type 89.0\%; MSS/ $B R A F^{V 600 E} 70.0 \% . P=0.031$ for log-rank test (Mantel-Cox); MSS/BRAF ${ }^{V 600 E}$ vs MSS/BRAF wild type.

Table 4. Overall, colorectal cancer disease-specific and disease-free survival by tumor subtype, HRs followed by Cls for Cox regression

\begin{tabular}{|c|c|c|c|c|c|c|c|}
\hline Tumour subtype & $N$ & $\begin{array}{l}\text { Overall survival } \\
\text { HR }(95 \% \mathrm{Cl})\end{array}$ & $P$ & $\begin{array}{c}\text { Disease-specific survival } \\
\text { HR }(95 \% \mathrm{Cl})\end{array}$ & $P$ & $\begin{array}{c}\text { Disease-free survival } \\
\text { HR }(95 \% \mathrm{Cl})\end{array}$ & $P$ \\
\hline MSS/BRAF-wild-type & 600 & 1 & & 1 & & 1 & \\
\hline $\mathrm{MSI} / B R A F^{V 600 E}$ & 60 & $0.83(0.54-1.27)$ & 0.386 & $0.58(0.28-1.18)$ & 0.131 & $0.42(0.18-0.96)$ & 0.039 \\
\hline MSI/BRAF-wild-type & 44 & $1.16(0.68-1.97)$ & 0.579 & $1.04(0.48-2.25)$ & 0.93 & $0.86(0.40-1.85)$ & 0.694 \\
\hline$M S S / B R A F^{V 600 E}$ & 34 & $1.87(1.17-3.00)$ & 0.009 & $1.88(1.06-3.31)$ & 0.03 & $1.36(0.59-3.15)$ & 0.468 \\
\hline
\end{tabular}

We observed a large overlap between MSI and $B R A F^{V 600 E}$ tumours, with 60 of the $94 B R A F^{V 600 E}$ tumours $(64 \%)$ also classified as MSI. Interestingly, the poor survival effect caused by $B R A F^{V 600 E}$ was practically overpowered by the favourable effect of MSI in the MSI/ $B R A F^{V 600 E}$ subgroup. Hence, MSI status should always be included in studies that address BRAF mutation status (Hamilton, 2013).

Some clinical features of MSI have been well described over the last two decades. The nearly $15 \%$ prevalence of MSI in our study is comparable to previously reported values (Ionov et al, 1993) and to a similar series in northern Europe (Merok et al, 2013), but not to the prevalence in EPICOLON (7.4\%; Moreira et al, 2012). Microsatellite instability tumours are more commonly situated in the proximal colon, whereas MSS tumours tend to be equally distributed between proximal and distal sites (Kim et al, 1994; Gryfe et al, 2000; Yang et al, 2010; Corso et al, 2013). As found in our present material, histology substantially differs between MSI tumours and those with proficient MMR. Microsatellite instability tumours often have a mucinous phenotype, and show intraepithelial and peritumoural lymphocytic infiltration and prominent inflammatory reaction compared with chromosomally instable tumours (Lothe et al, 1993; Thibodeau et al, 1993; Gryfe et al, 2000; Popat, 2004).

Our findings confirmed that female gender was associated with increasing MSI prevalence with age, while MSI frequency remained 
stable in men despite age. Most recent studies have also described an association of female gender with MSI (Malkhosyan et al, 2000; Malesci et al, 2007; Phipps et al, 2015). The increase of incidence has been proposed to be based on the effects of oestrogen withdrawal with increasing age, as oestrogen protects against tumour instability by decreasing the promoter methylation (Miyakura et al, 2001; Laghi et al, 2003). The female gender predominance may also be linked to a serrated pathway. Serrated pathway proximal adenocarcinomas are concentrated in females (Samadder et al, 2013), even though serrated adenomas are more common in males (Tuppurainen et al, 2005). In our present study material, female patients had more proximal colon tumours than men, and MSI was significantly more common in proximal tumours. It remains unknown why women have a higher rate of conversing serrated adenomas into adenocarcinomas, but sporadic MSI carcinomas are more frequent in women, occur at an older age, and often have a serrated morphology (Young et al, 2001). Patients who exhibit sporadic colon cancer within 5 years after colonoscopy are more likely to have an MSI tumour than those who are diagnosed $>5$ years after their last colonoscopy (Nishihara et al, 2013). They are also more likely to be female and to have tumours at a proximal location in the colon (Erichsen et al, 2013). About 18\% of proximal adenocarcinomas in women are serrated and they are linked to MSI predominance, which may provide a clinically relevant reason for close follow-up of serrated right adenomas in females (Snover et al, 2005; Mäkinen, 2007).

The current study has several limitations. All molecular analyses were conducted blinded to the clinical data, but the patient history and follow-up were obtained from the medical records and are thus retrospective by nature. The subgroup analyses are statistically solid, but the case numbers are small-especially regarding rectal cancer-and should be interpreted with caution. In addition, the clinical relevance of MSI as a prognostic factor has been criticised because most previous population-based studies have analysed samples from the 1980s and 1990s, before many modern developments in tumour staging and adjuvant chemotherapy (Malesci et al, 2007). Furthermore, one large well-designed study did not show that MSI influences prognosis (Barnetson et al, 2006). It is problematic to analyse the OS advantage of patients with MSI tumours, as many patients develop sporadic MSI CRC at an old age and other causes of death complicate the analysis (Malesci et al, 2007). Strengths of our study are that our material was from a defined catchment area and was collected entirely within the era during which staging was based on current guidelines; therefore, our data can be interpreted to corroborate the favourable effect of MSI. We also provided DFS and DSS in addition to OS, as well as an adequate follow-up length compared with studies with OS only (Toon et al, 2013). Our cohort of patients is well characterised and the follow-up time is long, but it is evident that further studies using other independent cohorts would be valuable to validate our results and conclusions. Therefore, we are seeking for collaboration with other groups of investigators with large and representative patient materials.

Overall, our data support the easy and inexpensive universal IHC screening of all CRC tumours for MSI and BRAF status. Tumour MSI can predict a lower risk of cancer-related deathregardless of standard prognostic factors, including tumour local invasion, but not independently of TNM classification. TNM classification only accounts for the current disease stage without predicting how aggressively the tumour may behave or how effective the immune response will be in defence. Some subgroups of patients may perform worse despite a less advanced TNM stage, thus warranting more specific subtyping of CRC. Microsatellite instability and BRAF are likely to complement the TNM classification and provide additional value to clinical prognostic evaluation.

\section{ACKNOWLEDGEMENTS}

This study received funding from the Mary and Georg C. Ehrnrooth Foundation, the University of Eastern Finland (grant no. B1401), the Sigrid Juselius Foundation, and the Finnish Cancer Foundation. We like to thank Mrs Kirsi Pylvänäinen, Mr Reino Pitkänen, Mr Juha Manninen, and Ms Minttu Mattila for their technical assistance.

\section{REFERENCES}

Aparicio T, Schischmanoff O, Poupardin C, Soufir N, Angelakov C, Barrat C, Levy V, Choudat L, Cucherousset J, Boubaya M, Lagorce C, Guetz Des G, Wind P, Benamouzig R (2012) Deficient mismatch repair phenotype is a prognostic factor for colorectal cancer in elderly patients. Dig Liver Dis 45: 245-250.

Barnetson RA, Tenesa A, Farrington SM, Nicholl ID, Cetnarskyj R, Porteous ME, Campbell H, Dunlop MG (2006) Identification and survival of carriers of mutations in DNA mismatch-repair genes in colon cancer. N Engl J Med 354: 2751-2763.

Belt EJT, Velde te EA, Krijgsman O, Brosens RPM, Tijssen M, van Essen HF, HBAC Stockmann, Bril H, Carvalho B, Ylstra B, Bonjer HJ, Meijer GA (2012) High lymph node yield is related to microsatellite instability in colon cancer. Ann Surg Oncol 19: 1222-1230.

Benatti P (2005) Microsatellite instability and colorectal cancer prognosis. Clin Cancer Res 11: 8332-8340.

Berg M, Guriby M (2013) Influence of microsatellite instability and KRAS and BRAF mutations on lymph node harvest in stage I-III colon cancers. Mol Med 19: 1.

Boissière-Michot F, Lazennec G, Frugier H, Jarlier M, Roca L, Duffour J, Paty Du E, Laune D, Blanchard F, Le Pessot F, Sabourin J-C, Bibeau F (2014) Characterization of an adaptive immune response in microsatellite-instable colorectal cancer. Oncoimmunology 3: e29256.

Boland CR, Thibodeau SN, Hamilton SR, Sidransky D, Eshleman JR, Burt RW, Meltzer SJ, Rodriguez-Bigas MA, Fodde R, Ranzani GN, Srivastava S (1998) A National Cancer Institute Workshop on Microsatellite Instability for cancer detection and familial predisposition: development of international criteria for the determination of microsatellite instability in colorectal cancer. Cancer Res 58: 5248-5257.

Corso G, Pascale V, Flauti G, Ferrara F, Marrelli D, Roviello F (2013) Oncogenic mutations and microsatellite instability phenotype predict specific anatomical subsite in colorectal cancer patients. Eur J Hum Genet 21: 1383-1388.

Erichsen R, Baron JA, Stoffel EM, Laurberg S, Sandler RS, Sørensen HT (2013) Characteristics and survival of interval and sporadic colorectal cancer patients: a nationwide population-based cohort study. Am J Gastroenterol 108: $1332-1340$.

Funkhouser WK, Lubin IM, Monzon FA, Zehnbauer BA, Evans JP, Ogino S, Nowak JA (2012) Relevance, pathogenesis, and testing algorithm for mismatch repair-defective colorectal carcinomas: a report of the association for molecular pathology. J Mol Diagn 14: 91-103.

Galon J, Mlecnik B, Bindea G, Angell HK, Berger A, Lagorce C, Lugli A, Zlobec I, Hartmann A, Bifulco C, Nagtegaal ID, Palmqvist R, Masucci GV, Botti G, Tatangelo F, Delrio P, Maio M, Laghi L, Grizzi F, Asslaber M, D'Arrigo C, Vidal-Vanaclocha F, Zavadova E, Chouchane L, Ohashi PS, Hafezi-Bakhtiari S, Wouters BG, Roehrl M, Nguyen L, Kawakami Y, Hazama S, Okuno K, Ogino S, Gibbs P, Waring P, Sato N, Torigoe T, Itoh K, Patel PS, Shukla SN, Wang Y, Kopetz S, Sinicrope FA, Scripcariu V, Ascierto PA, Marincola FM, Fox BA, Pagès F (2014) Towards the introduction of the 'Immunoscore' in the classification of malignant tumours. J Pathol 232: 199-209.

Gryfe R, Kim H, Hsieh ET, Aronson MD, Holowaty EJ, Bull SB, Redston M, Gallinger S (2000) Tumor microsatellite instability and clinical outcome in young patients with colorectal cancer. N Engl J Med 342: 69-77.

Guidoboni M, Gafà R, Viel A, Doglioni C, Russo A, Santini A, Del Tin L, Macrì E, Lanza G, Boiocchi M, Dolcetti R (2001) Microsatellite instability and high content of activated cytotoxic lymphocytes identify colon cancer patients with a favorable prognosis. Am J Pathol 159: $297-304$. 
Hamilton SR (2013) BRAF mutation and microsatellite instability status in colonic and rectal carcinoma: context really does matter. J Natl Cancer Inst 105: $1075-1077$.

Hutchins G, Southward K, Handley K, Magill L, Beaumont C, Stahlschmidt J, Richman S, Chambers P, Seymour M, Kerr D, Gray R, Quirke P (2011) Value of mismatch repair, KRAS, and BRAF mutations in predicting recurrence and benefits from chemotherapy in colorectal cancer. J Clin Oncol 29: 1261-1270.

Ionov Y, Peinado MA, Malkhosyan S, Shibata D, Perucho M (1993) Ubiquitous somatic mutations in simple repeated sequences reveal a new mechanism for colonic carcinogenesis. Nature 363: 558-561.

Kim H, Jen J, Vogelstein B, Hamilton SR (1994) Clinical and pathological characteristics of sporadic colorectal carcinomas with DNA replication errors in microsatellite sequences. Am J Pathol 145: 148-156.

Laghi L, Bianchi P, Malesci A (2003) Gender difference for promoter methylation pattern of hMLH1 and p16 in sporadic MSI colorectal cancer. Gastroenterology 124: 1165-1166.

Lochhead P, Kuchiba A, Imamura Y, Liao X, Yamauchi M, Nishihara R, Qian ZR, Morikawa T, Shen J, Meyerhardt JA, Fuchs CS, Ogino S (2013) Microsatellite instability and BRAF mutation testing in colorectal cancer prognostication. J Natl Cancer Inst 105: 1151-1156.

Lothe RA, Peltomäki P, Meling GI, Aaltonen LA, Nyström-Lahti M, Pylkkänen L, Heimdal K, Andersen TI, Moller P, Rognum TO (1993) Genomic instability in colorectal cancer: relationship to clinicopathological variables and family history. Cancer Res $\mathbf{5 3}$ : 5849-5852.

Malesci A, Laghi L, Bianchi P, Delconte G, Randolph A, Torri V, Carnaghi C, Doci R, Rosati R, Montorsi M, Roncalli M, Gennari L, Santoro A (2007) Reduced likelihood of metastases in patients with microsatellite-unstable colorectal cancer. Clin Cancer Res 13: 3831-3839.

Malkhosyan SR, Yamamoto H, Piao Z, Perucho M (2000) Late onset and high incidence of colon cancer of the mutator phenotype with hypermethylated hMLH1 gene in women. Gastroenterology 119: 598.

Mäkinen MJ (2007) Colorectal serrated adenocarcinoma. Histopathology 50: $131-150$.

Merok MA, Ahlquist T, Royrvik EC, Tufteland KF, Hektoen M, Sjo OH, Mala T, Svindland A, Lothe RA, Nesbakken A (2013) Microsatellite instability has a positive prognostic impact on stage II colorectal cancer after complete resection: results from a large, consecutive Norwegian series. Ann Oncol 24: 1274-1282.

Miyakura Y, Sugano K, Konishi F, Ichikawa A, Maekawa M, Shitoh K, Igarashi S, Kotake K, Koyama Y, Nagai H (2001) Extensive methylation of hMLH1 promoter region predominates in proximal colon cancer with microsatellite instability. Gastroenterology 121: 1300-1309.

Moreira L, Balaguer F, Lindor N, la Chapelle de A, Hampel H, Aaltonen LA, Hopper JL, Le Marchand L, Gallinger S, Newcomb PA, Haile R, Thibodeau SN, Gunawardena S, Jenkins MA, Buchanan DD, Potter JD, Baron JA, Ahnen DJ, Moreno V, Andreu M, Ponz de Leon M, Rustgi AK, Castells A. EPICOLON Consortium (2012) Identification of Lynch syndrome among patients with colorectal cancer. JAMA 308: 1555-1565.

Nishihara R, Wu K, Lochhead P, Morikawa T, Liao X, Qian ZR, Inamura K, Kim SA, Kuchiba A, Yamauchi M, Imamura Y, Willett WC, Rosner BA, Fuchs CS, Giovannucci E, Ogino S, Chan AT (2013) Long-term colorectalcancer incidence and mortality after lower endoscopy. N Engl J Med 369: 1095-1105.

Ogino S, Nosho K, Kirkner GJ, Kawasaki T, Meyerhardt JA, Loda M, Giovannucci EL, Fuchs CS (2009) CpG island methylator phenotype, microsatellite instability, BRAF mutation and clinical outcome in colon cancer. Gut 58: 90-96.

Ogino S, Shima K, Meyerhardt JA, McCleary NJ, Ng K, Hollis D, Saltz LB, Mayer RJ, Schaefer P, Whittom R, Hantel A, Benson AB, Spiegelman D, Goldberg RM, Bertagnolli MM, Fuchs CS (2012) Predictive and prognostic roles of BRAF mutation in stage III colon cancer: results from intergroup trial CALGB 89803. Clin Cancer Res 18: 890-900.

Palomaki GE, McClain MR, Melillo S, Hampel HL, Thibodeau SN (2009) EGAPP supplementary evidence review: DNA testing strategies aimed at reducing morbidity and mortality from Lynch syndrome. Genet Med 11: $42-65$.

Phipps AI, Buchanan DD, Makar KW, Burnett-Hartman AN, Coghill AE, Passarelli MN, Baron JA, Ahnen DJ, Win AK, Potter JD, Newcomb PA (2012) BRAF mutation status and survival after colorectal cancer diagnosis according to patient and tumor characteristics. Cancer Epidemiol Biomarkers Prev 21: 1792-1798.

Phipps AI, Limburg PJ, Baron JA, Burnett-Hartman AN, Weisenberger DJ, Laird PW, Sinicrope FA, Rosty C, Buchanan DD, Potter JD, Newcomb PA (2015) Association between molecular subtypes of colorectal cancer and patient survival. Gastroenterology 148: 77-87e2.

Popat S (2004) Systematic review of microsatellite instability and colorectal cancer prognosis. J Clin Oncol 23: 609-618.

Richards CH, Roxburgh CSD, Powell AG, Foulis AK, Horgan PG, McMillan DC (2014) The clinical utility of the local inflammatory response in colorectal cancer. Eur J Cancer 50: 309-319.

Roth AD, Tejpar S, Delorenzi M, Yan P, Fiocca R, Klingbiel D, Dietrich D, Biesmans B, Bodoky G, Barone C, Aranda E, Nordlinger B, Cisar L, Labianca R, Cunningham D, Van Cutsem E, Bosman F (2010) Prognostic role of KRAS and BRAF in stage II and III resected colon cancer: results of the translational study on the PETACC-3, EORTC 40993, SAKK 60-00 trial. J Clin Oncol 28: 466-474.

Samadder NJ, Vierkant RA, Tillmans LS, Wang AH, Weisenberger DJ, Laird PW, Lynch CF, Anderson KE, French AJ, Haile RW, Potter JD, Slager SL, Smyrk TC, Thibodeau SN, Cerhan JR, Limburg PJ (2013) Associations between colorectal cancer molecular markers and pathways with clinicopathologic features in older women. Gastroenterology 145: 348-356e1-2.

Samowitz WS, Sweeney C, Herrick J, Albertsen H, Levin TR, Murtaugh MA, Wolff RK, Slattery ML (2005) Poor survival associated with the BRAF V600E mutation in microsatellite-stable colon cancers. Cancer Res 65: 6063-6069.

Sargent DJ, Marsoni S, Monges G, Thibodeau SN, Labianca R, Hamilton SR, French AJ, Kabat B, Foster NR, Torri V, Ribic C, Grothey A, Moore M, Zaniboni A, Seitz J-F, Sinicrope F, Gallinger S (2010) Defective mismatch repair as a predictive marker for lack of efficacy of fluorouracil-based adjuvant therapy in colon cancer. J Clin Oncol 28: 3219-3226.

Shia J (2008) Immunohistochemistry versus microsatellite instability testing for screening colorectal cancer patients at risk for hereditary nonpolyposis colorectal cancer syndrome. Part I. The utility of immunohistochemistry. J Mol Diagn 10: 293-300.

Sloothaak DAM, Grewal S, Doornewaard H, van Duijvendijk P, Tanis PJ, Bemelman WA, van der Zaag ES, Buskens CJ (2014) Lymph node size as a predictor of lymphatic staging in colonic cancer. Br J Surg 101: 701-706.

Snover DC, Jass JR, Fenoglio-Preiser C, Batts KP (2005) Serrated polyps of the large intestine: a morphologic and molecular review of an evolving concept. Am J Clin Pathol 124: 380-391.

Thibodeau SN, Bren G, Schaid D (1993) Microsatellite instability in cancer of the proximal colon. Science 260: 816-819.

Thiel A, Heinonen M, Kantonen J, Gylling A, Lahtinen L, Korhonen M, Kytölä S, Mecklin J-P, Orpana A, Peltomäki P, Ristimäki A (2013) BRAF mutation in sporadic colorectal cancer and Lynch syndrome. Virchows Arch 463: 613-621.

Thiel A, Ristimäki A (2013) Toward a molecular classification of colorectal cancer: the role of BRAF. Front Oncol 3: 281.

Toon CW, Chou A, Desilva K, Chan J, Patterson J, Clarkson A, Sioson L, Jankova L, Gill AJ (2013) BRAFV600E immunohistochemistry in conjunction with mismatch repair status predicts survival in patients with colorectal cancer. Mod Pathol 27(5): 644-650.

Tuppurainen K, Mäkinen JM, Junttila O, Liakka A, Kyllönen AP, Tuominen H, Karttunen TJ, Mäkinen MJ (2005) Morphology and microsatellite instability in sporadic serrated and non-serrated colorectal cancer. J Pathol 207: 285-294.

Vasen HFA, Blanco I, Aktán-Collán K, Gopie JP, Alonso A, Aretz S, Bernstein I, Bertario L, Burn J, Capella G, Colas C, Engel C, Frayling IM, Genuardi M, Heinimann K, Hes FJ, Hodgson SV, Karagiannis JA, Lalloo F, Lindblom A, Mecklin J-P, Møller P, Myrhøj T, Nagengast FM, Parc Y, Ponz de Leon M, Renkonen-Sinisalo L, Sampson JR, Stormorken A, Sijmons RH, Tejpar S, Thomas HJW, Rahner N, Wijnen JT, Järvinen HJ, Möslein G. Mallorca group (2013) Revised guidelines for the clinical management of Lynch syndrome (HNPCC): recommendations by a group of European experts. Gut 62: 812-823.

Weissman SM, Burt R, Church J, Erdman S, Hampel H, Holter S, Jasperson K, Kalady MF, Haidle JL, Lynch HT, Palaniappan S, Wise PE, Senter L (2012) Identification of individuals at risk for Lynch syndrome using targeted evaluations and genetic testing: National Society of Genetic Counselors 
and the Collaborative Group of the Americas on Inherited Colorectal Cancer joint practice guideline. J Genet Couns 21: 484-493.

Yang Z, Oki E, Ando K, Morita M, Kakeji Y, Maehara Y (2010) The impact of a high-frequency microsatellite instability phenotype on the tumor location-related genetic differences in colorectal cancer. Cancer Genet Cytogenet 196: 133-139.

Young J, Simms LA, Biden KG, Wynter C, Whitehall V, Karamatic R, George J, Goldblatt J, Walpole I, Robin SA, Borten MM, Stitz R, Searle J, McKeone D, Fraser L, Purdie DR, Podger K, Price R, Buttenshaw R, Walsh MD, Barker M, Leggett BA, Jass JR (2001) Features of colorectal cancers with high-level microsatellite instability occurring in familial and sporadic settings: parallel pathways of tumorigenesis. Am J Pathol 159: $2107-2116$.

This work is published under the standard license to publish agreement. After 12 months the work will become freely available and the license terms will switch to a Creative Commons AttributionNonCommercial-Share Alike 4.0 Unported License. 